Many developing countries, moreover, have been encouraged to follow the lead of developed countries. That is because energy experts have viewed traditional sources of renewable energy as too unreliable and inefficient to be of much value in larger efforts to meet global energy demand. In fact, many energy experts have maintained that sources of traditional renewable energy, such as fuel wood and charcoal for cooking and heating, should be the preferred energy source in developing countries, where poverty and limited technological expertise make them attractive and accessible.

Second, energy experts have often rendered a similar verdict for sources of new renewable energy, which they believe are too decentralized and small-scale to meet a significant portion of global energy demand. Like traditional sources of renewable energy, experts have viewed sources of new renewable energy, such as solar and wind power, to be largely of use in remote rural villages in developing countries far removed from the power grid or modern transportation systems.

This led to a false dichotomy that has become a standard aspect of global energy strategies: centralized sources of energy, largely driven by fossil fuels, make sense in the developed world, while decentralized sources of renewable energy, both traditional and new, should serve as potential sources of energy in the developing world where they can also be tested for their viability. This attitude spurred many 'demonstration projects' in scattered locations, mainly in Africa, where they became technological dinosaurs subject to extinction, largely because they were designed and implemented by outsiders.

As the issue of global warming has gained greater currency, and as the price of oil has climbed above US $\$ 140$ a barrel, these decadesold beliefs are rapidly fading. Global energy strategies are changing.

Over the past decade, and particularly over the past 5 years, the governments of Denmark, Germany, Japan and the USA have supported the development of both solar and wind energy. Such efforts have led to the creation of substantial domestic markets for solar and wind energy in several developed countries. Indeed, these markets are now much larger than markets in developing countries, where decentralized renewable energy installations are small in size and number. In developed countries, moreover, wind and solar power is now linked to the power grid, solving the intermittency problem inherent in these sources and providing a reliable source of income for those producing the energy. Increased output has also decreased costs. These recent trends, in turn, have led developing countries such as China and India to begin developing renewable energy industries focusing on both domestic and foreign demand.

No single strategy exists for expanding the use of renewable energy in developing countries. Rather, there is an increasing series of options

José Goldemberg (TWAS Fellow 1990) is professor of physics at the University of São Paulo in Brazil. related to the energy source.

For example, traditional biomass, which is more abundant in the tropics than in temperate climates and thus more common in developing countries than in developed countries, might require solutions drawn from the experience and expertise of local citizens - for instance, to improve the efficiency of cooking stoves. Meanwhile, mini-hydroelectric plants and geothermal energy systems are rapidly spreading in several developing countries, including Indonesia, the Philippines and Vietnam. Solar heating technologies designed for individual housing units have become commonplace in China. Biofuels have emerged as a principal source of transportation fuel in Brazil. Such efforts have made Brazil a global leader in the research and development of this renewable energy source.

What policies could accelerate the adoption of renewables in the developing world? Government mandates are important, as shown by Brazil's experience with biofuels. Developed countries have spearheaded initiatives for feed-in tariffs and renewable portfolio standards. European Union regulations, for example, call for $20 \%$ of all electricity to be generated from renewable energy sources and $10 \%$ of all transportation fuels to be derived from biofuels by 2020. Similar measures are becoming commonplace in the developing world. More than 40 countries have passed laws and regulations setting targets for renewable energy production and use. Many energy experts now believe that such measures will prove more effective than tax credits or subsidies.

All of these initiatives, which are now accelerating due to rapidly rising prices for fossil fuels and a growing consensus that climate change poses an unprecedented threat to the environment and global well-being, have made renewable energy the fastest growing energy sector. Between 2001 and 2005, renewable energy production increased $11 \%$ a year, while total energy production increased just 1.6\% a year. If such growth rates persist, renewable energy could account for some $20 \%$ of total world energy consumption by 2030.

It has been a long gestation period. Yet renewable energy might finally be emerging as the primary source of future energy supplies. This is good news for the developing world and even better news for the world as a whole. The Brundtland report's vision of a "sustainable energy in perpetuity", yet to be realized, might finally be on the horizon. After decades of dawdling, the world has finally awakened to the need to pursue such a goal.

\section{VIEWPOINT I Romain Murenzi Science is helping Rwanda give up the ghosts of the past}

Rwanda's recent success has depended, first, on sustained political and economic commitments from the highest levels of government, and, second, on a strategic vision that has allowed the nation to transform these commitments into policies and programmes that have had a positive impact on peoples' lives. We have also received generous support from international donors. When the genocide ended in 1994, the government initially focused on rebuilding the nation's educational systems from top to bottom. Over the past decade, student enrolment 筮 in primary education has doubled from 940,000 to 2 million, enrolment in secondary education has increased sevenfold from 50,000 to 350,000, and enrolment in higher education has increased more than tenfold from 3,000 to 40,000 . The goal is to create a more educated and skilled labour force. We have also sought to implement simple, appropriate technologies, especially those that can provide immediate benefits to Rwanda's most impoverished citizens. For example, we have developed a programme to distribute biogas stoves that use human waste and generate heat far more efficiently than wood stoves. More than $50 \%$ of all households in Rwanda now have these stoves, and plans call for all households to have them by 2012. This might sound like a small measure, especially when compared to the enormous challenges we face. Yet improved stoves often have a dramatic impact on the lives of people, particularly those living in rural areas. Children no longer spend long hours gathering wood and, as a result, spend more time in school. In addition, the measure reduces stress on the nation's forests and therefore helps to improve the environment. The government has also provided opportunities for farmers to adopt land-management practices such as terraced farming, and has encouraged them to work their land cooperatively to increase their prospects for producing crops for market. In the past, farm families tilled plots of land as small as one-quarter hectare and grew small amounts of a wide variety of crops, largely for their own consumption. Today, many farmers, as members of farm cooperatives, grow maize and produce milk for sale. Their efforts are aided by government agencies that provide training and carry out demonstrations free of charge. This is science-based development at its best. Simply put, we are turning to science to help improve peoples' lives. 